\title{
Healthcare utilization of overweight and obese Europeans aged 50-79 years
}

\author{
I. Peytremann-Bridevaux • B. Santos-Eggimann
}

Received: 2 January 2007 / Accepted: 5 March 2007 / Published online: 27 March 2007

(C) Springer-Verlag 2007

\begin{abstract}
To examine the association between overweight/ obesity and healthcare utilization in middle-aged and aged Europeans. This is a baseline cross-sectional analysis of self-reported data from ten countries participating in the Survey of Health, Ageing and Retirement in Europe (SHARE), which reached an overall response rate of $62 \%$. Included in the study were 16,695 non-institutionalized individuals aged 50-79 years with body mass indexes (BMI) $\geq 18.5 \mathrm{~kg} / \mathrm{m}^{2}$. We used height and weight to compute BMI and categorized it into normal weight (BMI 18.5$24.9 \mathrm{~kg} / \mathrm{m}^{2}$ ), overweight (BMI 25.0-29.9 $\mathrm{kg} / \mathrm{m}^{2}$ ) and obesity (BMI $\geq 30 \mathrm{~kg} / \mathrm{m}^{2}$ ). Dichotomous measures of healthcare utilization during the previous 12 months included any use of ambulatory care, high use of a general practitioner, visits to specialists, high use of medication, hospitalization, high number of times hospitalized and nights spent in the hospital, surgery, home healthcare and domestic help. Logistic regressions adjusted for age, socio-economic status, smoking, physical activity, alcohol consumption, country of residence, and chronic conditions. All analyses were stratified by gender. Among men and women, being overweight or obese was associated with a significantly
\end{abstract}

I. Peytremann-Bridevaux $(\bowtie) \cdot$ B. Santos-Eggimann

Health Services Research Unit,

Institute of Social and Preventive Medicine,

University of Lausanne,

17 Bugnon,

CH-1005 Lausanne, Switzerland

e-mail: Isabelle.Peytremann-Bridevaux@chuv.ch

I. Peytremann-Bridevaux

Institute of Health Economics and Management,

University of Lausanne,

9 César-Roux,

CH-1005 Lausanne, Switzerland increased risk of using ambulatory care and visiting general practitioners, as well as taking $\geq 2$ medication categories. Those relationships were only partially explained by chronic conditions. Obese women were at increased risk and overweight men at decreased risk of hospitalization. For men, exploring other hospitalization dimensions did not reveal significant associations, however. Men and women, whether overweight or obese, did not report higher use of specialists, surgery, home healthcare or domestic help. For all outcomes, similar trends were found at the country level. Population-attributable fractions were highest for medication use, both for men $(23 \%)$ and women $(19 \%)$. Despite the rising prevalence of obesity and aging of the population, findings from SHARE show that overweight and obesity place a moderate burden on European healthcare systems, mostly by increasing ambulatory care and medication use.

Keywords Obesity · Overweight · Healthcare utilization · Population-based study

\section{Introduction}

In Europe, as in most other industrialized countries, population aging (Lloyd-Sherlock 2000) and the prevalence of overweight and obesity continue to rise over time (Flegal et al. 2002; Mokdad et al. 2001). The higher frequency of chronic diseases (Haslam and James 2005; Field et al. 2001), physical disability (Larrieu et al. 2004; Lean et al. 1999) and poorer health-related quality of life (Groessl et al. 2004; Arterburn et al. 2004; Fontaine and Barofsky 2001) of overweight/obese and elderly individuals drives healthcare utilization. This is of particular concern because it has been estimated that the rising prevalence of obesity is 
likely to reduce, or even reverse, the recent improvements in disability among the elderly (Sturm et al. 2004).

The issue of the burden that the overweight and obese place on the healthcare system in terms of healthcare utilization is of recent interest and has been increasingly commented on in the literature in the past few years (Bertakis and Azari 2005; Leon-Munoz et al. 2005; von Lengerke et al. 2005; Andreyeva et al. 2004; Meisinger et al. 2004; Raebel et al. 2004; Luchsinger et al. 2003; Guallar-Castillon et al. 2002; Ostbye et al. 2002; Reidpath et al. 2002; Quesenberry et al. 1999; Trakas et al. 1999; Fontaine et al. 1998). Despite the fact that the countries, populations considered, age range, utilization window time and confounding adjustment somewhat differed across studies, it has been shown that obesity is generally associated with higher ambulatory care visits and drug consumption, but not consistently with higher hospitalization rates. The majority of studies used North American data (Bertakis and Azari 2005; Andreyeva et al. 2004; Luchsinger et al. 2003; Reidpath et al. 2002; Quesenberry et al. 1999; Trakas et al. 1999; Fontaine et al. 1998), and an overall European picture is lacking. Exploring this issue across Europe would be of interest since healthcare accessibility is theoretically less problematic in Europe, compared to the United States. In Europe, actually, more than $90 \%$ of European residents are covered by public or private health insurance plans (Colombo and Tapay 2004).

In this study we aimed to assess the impact on health systems of overweight and obesity in European men and women. Therefore, we examined the association between body mass index (BMI) and a range of healthcare utilization measures, using standardized individual-level data allowing for comprehensive adjustment. We hypothesized that being either overweight or obese would be associated with a generally increased use of health services in both genders, irrespective of the country (and healthcare system) considered.

\section{Methods}

Setting, participants and data

This study involved the secondary analysis of data from the Survey of Health, Ageing and Retirement in Europe (SHARE) 2004, release 1 (Börsch-Supan et al. 2005). It may contain errors that will be corrected in later releases, but which would most probably not invalidate the current findings. Baseline cross-sectional data collection of noninstitutionalized individuals aged 50 years and over was organized in 2004 in each of the ten participating countries: Austria, Denmark, France, Germany, Greece, Italy, Spain, Sweden, Switzerland and the Netherlands. An overall response rate of $61.8 \%$ was obtained (Börsch-Supan and
Jürges 2005), with response rates varying from 50.2 to $73.6 \%$, except in Switzerland, which reached only $37.6 \%$. SHARE information was collected through standardized face-to-face interviews. We pooled the responses from all ten countries and restricted the sample to the 17,303 respondents aged 50 to 79 years old. Of those, we excluded $438(2.5 \%)$ persons with missing or implausible information regarding height, weight or body mass index, and 170 (1\%) underweight individuals $\left(\mathrm{BMI}<18.5 \mathrm{~kg} / \mathrm{m}^{2}\right)$. The working sample consisted of 16,695 subjects.

\section{Measures}

Height and weight were self-reported, and BMI was calculated as the weight in kilograms divided by the square of the height in meters $\left(\mathrm{kg} / \mathrm{m}^{2}\right)$. The participants were divided into three BMI categories: normal weight (BMI $18.5-24.9 \mathrm{~kg} / \mathrm{m}^{2}$ ), overweight (BMI $25.0-29.9 \mathrm{~kg} / \mathrm{m}^{2}$ ) and obesity (BMI $\geq 30.0 \mathrm{~kg} / \mathrm{m}^{2}$ ).

Healthcare utilization during the previous 12 months included the reported number of ambulatory care visits, and among respondents with at least one ambulatory care visit, data were collected on the number of visits to general practitioners and whether specialists were consulted (yes/ no); hospitalization (yes/no), and among respondents who were hospitalized, data were collected on the number of separate hospital stays and on the total number of nights the respondent spent in the hospital; whether any surgery was required either as an in- or out-patient (yes/no); the number of medication categories taken at least once a week; the use of home healthcare (yes/no) and of domestic help (yes/no). The number of total and general practitioner ambulatory care visits, of separate hospitalizations, of the total number of nights spent in the hospital and medication categories taken were dichotomized into high ( $>$ sample median) and low ( $\leq$ sample median) use. For each of the latter outcomes, the median was determined separately for men and women.

Adjustment was considered for the following potential confounders: age, country of residence, marital status, socio-economic status as measured by years of education and purchasing power parity-household income (Euros) adjusted for the size of the household (ppp-household income), smoking, physical activity, alcohol consumption, supplementary insurance (any voluntary, supplementary or private health insurance) and physician-diagnosed chronic conditions related to obesity (heart disease including myocardial infarction, high blood pressure, high cholesterol, diabetes and arthritis). The goal of the adjustment for chronic conditions was to determine the extent to which associations between BMI and utilization could be explained by diseases known to be related to overweight or obesity. All the collected variables were self-reported. 
Statistical analysis

First, healthcare utilization was compared across BMI categories using chi-squared tests. Then, separate multiple regressions were used to assess the association between BMI and each utilization outcome variable, considering the normal weight category as the reference. Because home healthcare and domestic help questions were not asked of Greek and Swiss participants, those two countries were excluded from the analyses of these two outcomes. Three separate logistic regression models, which included the following variables, were built : model 1: age and country of residence; model 2: as model $1+$ socio-economic status, smoking, physical activity and alcohol consumption; model 3: as model $2+$ obesity-related chronic conditions. We also tested whether supplementary insurance status changed the point estimates by adjusting for it in model 2 . The joint Wald test was used to evaluate interactions between the following categorical variables: BMI and countries, and BMI and age categories (50-64 years/65-79 years). In the working sample, none of the variables considered had $\geq 2 \%$ missing data.

For the statistically significant associations between overweight/obesity and healthcare utilization, we assessed population-attributable fractions (PAF). This was done using the equation $\mathrm{PAF}=p$ * $(\mathrm{OR}-1 / \mathrm{OR})$ where $\mathrm{OR}$ is the adjusted odds ratio for overweight or obesity, and $p$ represents the proportion of patients that were overweight or obese (Rockhill et al. 1998). The PAF values for overweight and obesity represent the proportion of cases of healthcare utilization that we could expect to be prevented if overweight and obesity were eliminated.

All analyses (except country-level analysis) were stratified by gender and performed using Stata 8.0. $P$ values $<$ 0.05 were considered significant.

\section{Results}

According to SHARE, $50.7 \%$ of European men aged 50 to 79 years were overweight and $16.2 \%$ were obese, while $36.9 \%$ of European women of similar age were overweight and $19.1 \%$ obese. The estimated prevalences of overweight and obesity across countries and gender are described in Table 1. They highlight that Austria, Greece and Spain had the highest prevalence of obesity among both men and women. Characteristics of the study population are presented by gender in Table 2 .

Table 3 shows the unadjusted comparisons of health services utilization during the previous 12 months, by BMI category and gender. Except for visits to specialists and surgery, utilization significantly increased with higher BMI both for men and women. Hospitalization and home health services were only significantly more prevalent among overweight and obese women. The adjusted odds ratios are presented in Table 4. Among men and women, overweight and obesity were associated with a significantly increased risk of having any ambulatory care visit, being a high user of ambulatory care visits, being a high user of general practitioner visits and being a high user of medication. These associations between BMI and healthcare utilization were not fully explained by obesity-related chronic conditions, suggesting that only part of the use may be attributable to these diseases.

For all the non-significant associations found using model 3, subdividing obesity (BMI $\geq 30 \mathrm{~kg} / \mathrm{m}^{2}$ ) into obesity class I (BMI $30.0-34.9 \mathrm{~kg} / \mathrm{m}^{2}$ ) and obesity class II and III $\left(B M I \geq 35.0 \mathrm{~kg} / \mathrm{m}^{2}\right)$ showed similar results. When we consider only fully adjusted odds ratios (model 3) that were significant, the subdivision of BMI into more categories revealed a slight, but not consistently significant "dose-response" relationship for high use of general
Table 1 Estimated prevalence of overweight (BMI 25.0 $29.9 \mathrm{~kg} / \mathrm{m}^{2}$ ) and obesity $\left(\mathrm{BMI} \geq 30.0 \mathrm{~kg} / \mathrm{m}^{2}\right)$ by gender and country $(n=16,695)$

\begin{tabular}{|c|c|c|c|c|c|}
\hline & \multirow[b]{2}{*}{ Working sample size (n) } & \multicolumn{2}{|c|}{ Men $(n=7,854)$} & \multicolumn{2}{|c|}{ Women $(\mathrm{n}=8,841)$} \\
\hline & & Overweight & Obese & Overweight & Obese \\
\hline Austria & 1,697 & $52.3 \%$ & $18.6 \%$ & $35.7 \%$ & $21.1 \%$ \\
\hline Denmark & 1,384 & $46.1 \%$ & $14.9 \%$ & $33.0 \%$ & $14.5 \%$ \\
\hline France & 1,449 & $48.4 \%$ & $15.4 \%$ & $30.3 \%$ & $16.6 \%$ \\
\hline Germany & 2,096 & $51.6 \%$ & $17.2 \%$ & $38.5 \%$ & $18.5 \%$ \\
\hline Greece & 1,725 & $55.5 \%$ & $17.8 \%$ & $41.3 \%$ & $23.6 \%$ \\
\hline Italy & 1,804 & $51.6 \%$ & $16.1 \%$ & $39.2 \%$ & $19.5 \%$ \\
\hline The Netherlands & 2,041 & $48.3 \%$ & $14.9 \%$ & $36.7 \%$ & $18.1 \%$ \\
\hline Spain & 1,433 & $49.9 \%$ & $21.0 \%$ & $41.0 \%$ & $26.9 \%$ \\
\hline Sweden & 2,253 & $47.8 \%$ & $14.2 \%$ & $36.5 \%$ & $15.6 \%$ \\
\hline Switzerland & 813 & $46.7 \%$ & $13.3 \%$ & $29.7 \%$ & $13.1 \%$ \\
\hline All 10 countries & 16,695 & $50.7 \%$ & $16.2 \%$ & $36.9 \%$ & $19.1 \%$ \\
\hline
\end{tabular}


Table 2 Characteristics of the SHARE studied population, by gender $(\mathrm{n}=16,695)$

\begin{tabular}{|c|c|c|}
\hline & $\begin{array}{l}\text { Men } \\
(\mathrm{n}= \\
7,854)\end{array}$ & $\begin{array}{l}\text { Women } \\
(\mathrm{n}= \\
8,841)\end{array}$ \\
\hline Age, mean (SD) & $\begin{array}{l}62.4 \\
(0.15)\end{array}$ & $\begin{array}{l}63.2 \\
(0.14)\end{array}$ \\
\hline Years of education, mean (SD) & $\begin{array}{l}10.6 \\
(0.09)\end{array}$ & $\begin{array}{l}9.4 \\
(0.08)\end{array}$ \\
\hline \multicolumn{3}{|c|}{ Ppp-household income adjusted for household size (Euros) } \\
\hline 25 th percentile & 13,308 & 10,889 \\
\hline 50th percentile & 23,295 & 19,620 \\
\hline 75th percentile & 39,459 & 34,520 \\
\hline Married or registered partnership, $\%$ & 79.2 & 63.6 \\
\hline Currently smoking, $\%$ & 25.9 & 14.6 \\
\hline $\begin{array}{l}\text { Neither moderate nor vigorous } \\
\text { physical activity, \% }\end{array}$ & 7.8 & 10.6 \\
\hline $\begin{array}{l}\text { Drinking } \geq 2 \text { glasses of alcohol } \\
5 / 6 \text { days a week, } \%\end{array}$ & 27.5 & 7.1 \\
\hline \multicolumn{3}{|l|}{ Number of physician's diagnosed chronic diseases ${ }^{\text {a }}, \%$} \\
\hline 0 & 29.8 & 24.7 \\
\hline 1 & 33.8 & 32.0 \\
\hline 2 or more & 36.4 & 43.2 \\
\hline \multicolumn{3}{|l|}{2 or more health complaints ${ }^{\mathrm{b}}, \%$} \\
\hline 0 & 37.9 & 24.8 \\
\hline 1 & 34.4 & 31.5 \\
\hline 2 or more & 27.7 & 43.6 \\
\hline $\begin{array}{l}\text { Fair or poor subjective health (vs. excellent/very } \\
\text { good/good), } \%\end{array}$ & 29.7 & 35.5 \\
\hline $\begin{array}{l}\text { Difficulties in any of five activities of daily living } \\
\text { (bathing, dressing, eating, walking across a } \\
\text { room and getting in or out of bed), } \%\end{array}$ & 8.5 & 7.0 \\
\hline
\end{tabular}

aPhysicians' diagnosed chronic conditions ("Has a doctor ever toldyou that you had any of the conditions on this card?"): high blood pressure or hypertension; high blood cholesterol; stroke or cerebrovascular disease; diabetes or high blood sugar; chronic lung disease such as bronchitis or emphysema; asthma; arthritis, including osteoarthritis or rheumatism; osteoporosis; cancer or malignant tumor, including leukemia or lymphoma, but excluding minor skin cancers; stomach or duodenal ulcer, peptic ulcer; Parkinson's disease; cataract; hip fracture or femoral fracture; other condition, not yet mentioned.

${ }^{\mathrm{b}}$ Health complaints ("For the past 6 months, have you been bothered by any of the health conditions on this card?"): pain in your back, knees, hips or any other joint; heart trouble or angina, chest pain during exercise; breathlessness, difficulty breathing; persistent cough; swollen legs; sleeping problems; falling down; fear of falling down; dizziness, faints or blackouts; stomach or intestine problems, including constipation, air, diarrhea; incontinence or involuntary loss of urine; other symptom, not yet mentioned.

practitioners in men (model 3: obesity class I: OR 1.5, 95\% CI 1.2-2.0; obesity class II-III: OR $1.8,95 \%$ CI $1.1-3.0$ ) and for polymedication in both men (model 3: obesity class I: OR $1.3,95 \%$ CI $0.9-1.7$; obesity class II-III: OR $1.9,95 \%$ CI 1.1-3.1) and women (model 3: obesity class I: OR $1.6,95 \%$ CI 1.3-2.1; obesity class II-III: OR 2.2, 95\% CI 1.5-3.2).
With respect to hospitalization, the risk decreased for overweight men, but rose for obese women. However, this decreased risk of hospitalization for overweight men was only marginally significant, and exploring two different components of men's hospitalization (times hospitalized, nights spent in hospital) did not disclose significant associations. Men and women, whether overweight or obese, did not report significantly higher use of specialists, surgery, home healthcare or domestic help. The increased use of home services observed in obese women was explained by socio-economic status and behavioral risk factors.

Because the country variable might be considered as an effect modifier of the association BMI-healthcare utilization, we performed country-level analyses. The latter was performed on pooled data for men and women because the utilization results did not differ much by gender, and country sample sizes were reduced. After adjustment for age, gender, socio-economic status and behavioral risk factors, results showed similar trends in odds ratios for ambulatory care visits, general practitioner visits, medication use, hospitalization and surgery. Utilization of specialists varied more across countries, with Austrian, French, German, Greek, Spanish and Swedish overweight and/or obese participants tending to report less use of specialists during the previous 12 months. The latter odds ratios were not significant, however.

Statistically, none of the associations between BMI and healthcare utilization varied by age category or country of residence (test for BMI*age and BMI*country interactions, $P>0.05$ ), and none of the point estimates changed when considering supplementary insurance as another confounding variable.

The population attributable fractions for high use of ambulatory care were $3 \%$ for overweight and obese men and $12 \%$ for overweight and obese women. PAFs for high use of general practitioners were $15 \%$ and $13 \%$ for overweight and obese men and women, respectively, and $23 \%$ for men and $19 \%$ for women for high use of medications. Among women, hospitalization could be ascribed to overweight and obesity in $12 \%$ of the cases.

\section{Discussion}

Our results show that in Europe, for both men and women, being overweight and being obese were similarly associated with increased use of ambulatory care visits, general practitioner visits and medication use, but not with visits to specialists, surgery, home healthcare or domestic help. As shown using three separate logistic regression models, these associations did not appear to depend on the individuals' age, socio-economic status and behavioral risk factors. They may rather be related to the most frequently 
Table 3 Health services utilization during the previous 12 months, by BMI category and gender

\begin{tabular}{|c|c|c|c|c|}
\hline Men & $\begin{array}{l}\text { Normal weight } \\
(\mathrm{n}=2,597)\end{array}$ & $\begin{array}{l}\text { Overweight } \\
(\mathrm{n}=3,982)\end{array}$ & $\begin{array}{l}\text { Obesity } \\
(\mathrm{n}=1,275)\end{array}$ & $\mathrm{P}$ value \\
\hline At least one ambulatory care visit, $\%$ & $80.9 \%$ & $85.5 \%$ & $85.2 \%$ & $<0.01$ \\
\hline Specialist consulted, \% & $91.3 \%$ & $92.6 \%$ & $92.5 \%$ & 0.75 \\
\hline High use of ambulatory care ( $\geq 4$ visits), $\%$ & $43.5 \%$ & $51.6 \%$ & $62.8 \%$ & $<0.001$ \\
\hline High use of general practitioners ( $\geq 4$ visits), $\%$ & $40.1 \%$ & $47.0 \%$ & $59.2 \%$ & $<0.001$ \\
\hline Polymedication ( $\geq 2$ medication categories), $\%$ & $24.7 \%$ & $32.8 \%$ & $44.9 \%$ & $<0.001$ \\
\hline Hospitalization, \% & $14.6 \%$ & $12.1 \%$ & $14.9 \%$ & 0.09 \\
\hline \multicolumn{5}{|l|}{ Among those hospitalized: } \\
\hline -High use of hospital ( $\geq 2$ times/past 12 months) & $40.8 \%$ & $29.4 \%$ & $31.0 \%$ & 0.08 \\
\hline -High number of nights (overall, $\geq 7$ nights) & $57.4 \%$ & $52.4 \%$ & $56.4 \%$ & 0.61 \\
\hline Any surgery, \% & $12.2 \%$ & $10.5 \%$ & $11.0 \%$ & 0.32 \\
\hline Any home healthcare ${ }^{\mathrm{a}}, \%$ & $3.1 \%$ & $2.4 \%$ & $3.6 \%$ & 0.34 \\
\hline Any domestic help ${ }^{\mathrm{a}}, \%$ & $1.2 \%$ & $1.6 \%$ & $1.4 \%$ & 0.77 \\
\hline Women & $(\mathrm{n}=3,899)$ & $(\mathrm{n}=3,258)$ & $(\mathrm{n}=1,684)$ & \\
\hline At least one ambulatory care visit, $\%$ & $89 \%$ & $91.2 \%$ & $93.1 \%$ & $<0.01$ \\
\hline Specialist consulted, $\%$ & $95.2 \%$ & $94.5 \%$ & $95.2 \%$ & 0.76 \\
\hline High use of ambulatory care ( $\geq 5$ visits), $\%$ & $44.7 \%$ & $53.8 \%$ & $60.9 \%$ & $<0.001$ \\
\hline High use of general practitioners ( $\geq 4$ visits), $\%$ & $45.6 \%$ & $55.5 \%$ & $64.5 \%$ & $<0.001$ \\
\hline Polymedication ( $\geq 2$ medication categories), $\%$ & $31.7 \%$ & $42.5 \%$ & $58.4 \%$ & $<0.001$ \\
\hline Hospitalization, $\%$ & $11.2 \%$ & $13.5 \%$ & $16.8 \%$ & $<0.001$ \\
\hline \multicolumn{5}{|l|}{ Among those hospitalized: } \\
\hline -High use of hospitals ( $\geq 2$ times/past 12 months) & $25.3 \%$ & $24.5 \%$ & $28.3 \%$ & 0.74 \\
\hline -High number of nights (overall, $\geq 7$ nights) & $45.9 \%$ & $50.1 \%$ & $59.1 \%$ & 0.07 \\
\hline Any surgery, $\%$ & $12.3 \%$ & $13.1 \%$ & $12.0 \%$ & 0.69 \\
\hline Any home healthcare ${ }^{\mathrm{a}}, \%$ & $3.3 \%$ & $2.3 \%$ & $4.8 \%$ & $<0.01$ \\
\hline Any domestic help ${ }^{\mathrm{a}}, \%$ & $2.6 \%$ & $2.7 \%$ & $4.5 \%$ & 0.03 \\
\hline
\end{tabular}

${ }^{\mathrm{a}}$ Greece and Switzerland excluded from that analysis (see Methods section)

described obesity-related chronic conditions-particularly for obese individuals-and obesity itself. In addition, their direction was constant across countries and their healthcare systems, except for the use of specialists.

A large database of men and women from ten European countries, the use of standardized questionnaires and procedures, the availability of a data set allowing comprehensive adjustments and separate analyses for men and women were the main strengths of this study. However, a number of limitations have to be considered. The first was the fact that height and weight were self-reported. Because men and women generally overestimate their height and underestimate their weight, particularly if they are obese, BMI tends to be underestimated (Connor Gorber et al. 2007; Palta et al. 1982). Therefore, the true percentage of the overweight and obese population may be higher than our estimates, and the healthcare utilization adjusted associations are likely to be overestimated. Secondly, the overall response rate was modest $(62 \%)$, particularly due to a poor participation in Switzerland (37.8\%). Despite the latter, the age, sex, subjective health and BMI characteristics of the Swiss sample were similar to those of the 2002 Swiss Health Care Survey (unpublished results). Thirdly, even if social security or statutory health insurance coverage is almost universal in countries participating in SHARE, supplementary and private insurances might still improve access to care. Owing to their complexity, they cannot be fully adjusted for in analyses. However, considering the mere fact of reporting any supplementary insurance did not modify the results. Fourthly, due to the cross-sectional nature of the analysis, causality cannot be inferred. Whether overweight and/or obesity appeared before or after healthcare use cannot be determined. Even though part of the use that we model could be the effect of successful healthcare of overweight and obese individuals, such an inverse causality is very unlikely. Finally, the use of self-reported data could result in information and recall biases, and residual or unmeasured confounding cannot be excluded.

The healthcare systems of the ten countries included in the SHARE study are diverse. In each country, however, almost all citizens are covered by some type of health insurance (Colombo and Tapay 2004). Because the country of residence is associated both with BMI (the prevalence of excess weigh differs across countries) and healthcare utilization (different utilization patterns across countries), it was considered as a potential confounding variable. Furthermore, the country of residence may also have acted 
Table 4 Association between BMI and healthcare utilization (adjusted odds ratios) ${ }^{\mathrm{a}}$

\begin{tabular}{|c|c|c|c|c|c|c|}
\hline & \multicolumn{2}{|l|}{ Model 1} & \multicolumn{2}{|l|}{ Model 2} & \multicolumn{2}{|l|}{ Model 3} \\
\hline & Overweight & Obesity & Overweight & Obesity & Overweight & Obesity \\
\hline \multicolumn{7}{|l|}{ Men } \\
\hline At least one ambulatory care visit & $1.4(1.2-1.8)$ & $1.4(1.1-1.9)$ & $1.4(1.1-1.7)$ & $1.4(1.0-1.9)$ & $1.2(1.0-1.5)$ & $0.9(0.7-1.3)$ \\
\hline High use of ambulatory care ( $\geq 4$ visits) & $1.4(1.2-1.7)$ & $2.4(1.9-2.9)$ & $1.4(1.2-1.7)$ & $2.3(1.8-2.8)$ & $1.2(1.0-1.4)$ & $1.6(1.3-2.0)$ \\
\hline High use of general practitioners ( $\geq 4$ visits) & $1.4(1.1-1.6)$ & $2.4(1.9-3.0)$ & $1.3(1.1-1.6)$ & $2.2(1.7-2.7)$ & $1.2(1.0-1.4)$ & $1.6(1.2-2.0)$ \\
\hline Specialist consulted & $1.2(0.8-2.0)$ & $1.3(0.7-2.4)$ & $1.2(0.8-2.0)$ & $1.3(0.7-2.4)$ & $1.1(0.7-1.8)$ & $1.1(0.6-2.1)$ \\
\hline Polymedication ( $\geq 2$ medication categories) & $1.6(1.3-1.9)$ & $2.8(2.2-3.4)$ & $1.5(1.3-1.8)$ & $2.6(2.1-3.3)$ & $1.1(0.9-1.4)$ & $1.4(1.0-1.8)$ \\
\hline Hospitalization & $0.8(0.6-1.0)$ & $1.0(0.8-1.4)$ & $0.8(0.6-1.0)$ & $1.0(0.7-1.3)$ & $0.7(0.6-0.9)$ & $0.8(0.6-1.1)$ \\
\hline \multicolumn{7}{|l|}{ Among those hospitalized: } \\
\hline -High use of hospital ( $\geq 2$ times $/ 12 \mathrm{~m}$ ) & $0.6(0.4-1.0)$ & $0.7(0.4-1.2)$ & $0.7(0.4-1.1)$ & $0.7(0.4-1.3)$ & $0.7(0.4-1.1)$ & $0.7(0.4-1.3)$ \\
\hline -High overall number of nights ( $\geq 7$ nights) & $0.8(0.6-1.4)$ & $1.0(0.6-1.8)$ & $0.9(0.6-1.4)$ & $1.0(0.6-1.8)$ & $0.8(0.5-1.3)$ & $0.9(0.5-1.7)$ \\
\hline Any surgery & $0.9(0.7-1.1)$ & $0.9(0.7-1.2)$ & $0.8(0.7-1.0)$ & $0.8(0.6-1.1)$ & $0.8(0.6-1.1)$ & $0.8(0.5-1.0)$ \\
\hline Home healthcare $^{\mathrm{b}}$ & $0.9(0.5-1.4)$ & $1.3(0.7-2.6)$ & $0.8(0.5-1.3)$ & $1.2(0.7-2.5)$ & $0.8(0.5-1.3)$ & $1.1(0.6-2.2)$ \\
\hline Domestic help ${ }^{b}$ & $1.5(0.7-3.2)$ & $1.4(0.6-3.2)$ & $1.6(0.8-3.3)$ & $1.3(0.5-3.1)$ & $1.5(0.7-3.2)$ & $0.9(0.4-2.4)$ \\
\hline \multicolumn{7}{|l|}{ Women } \\
\hline At least one ambulatory care visit & $1.3(1.0-1.7)$ & $1.7(1.2-2.4)$ & $1.3(1.0-1.7)$ & $1.6(1.2-2.3)$ & $1.2(0.9-1.5)$ & $1.2(0.8-1.7)$ \\
\hline High use of ambulatory care ( $\geq 4$ visits) & $1.4(1.2-1.6)$ & $1.9(1.6-2.2)$ & $1.4(1.2-1.6)$ & $1.7(1.4-2.1)$ & $1.2(1.1-1.5)$ & $1.3(1.1-1.6)$ \\
\hline High use of general practitioners ( $\geq 4$ visits) & $1.5(1.3-1.8)$ & $2.2(1.8-2.7)$ & $1.5(1.2-1.7)$ & $1.9(1.6-2.4)$ & $1.3(1.1-1.5)$ & $1.5(1.2-1.8)$ \\
\hline Specialist consulted & $1.0(0.6-1.5)$ & $1.2(0.7-2.0)$ & $1.0(0.6-1.6)$ & $1.3(0.8-2.2)$ & $0.9(0.6-1.5)$ & $1.1(0.6-1.9)$ \\
\hline Polymedication ( $\geq 2$ medication categories) & $1.6(1.3-1.8)$ & $3.1(2.6-3.7)$ & $1.5(1.3-1.8)$ & $2.8(2.3-3.4)$ & $1.2(1.0-1.5)$ & $1.8(1.4-2.2)$ \\
\hline Hospitalization & $1.2(1.0-1.5)$ & $1.6(1.3-2.1)$ & $1.2(1.0-1.5)$ & $1.4(1.1-1.8)$ & $1.1(0.9-1.4)$ & $1.1(0.8-1.5)$ \\
\hline \multicolumn{7}{|l|}{ Among those hospitalized: } \\
\hline -High use of hospital ( $\geq 2$ times/12 m) & $0.9(0.6-1.5)$ & $1.1(0.7-1.9)$ & $1.0(0.6-1.6)$ & $1.0(0.6-1.7)$ & $1.0(0.6-1.6)$ & $1.1(0.6-1.9)$ \\
\hline -High overall number of nights ( $\geq 7$ nights) & $1.2(0.7-1.8)$ & $1.9(1.1-3.0)$ & $1.2(0.8-2.0)$ & $1.8(1.1-3.1)$ & $1.2(0.7-1.9)$ & $1.7(1.0-2.8)$ \\
\hline Any surgery & $1.1(0.9-1.4)$ & $1.0(0.8-1.3)$ & $1.1(0.9-1.4)$ & $1.0(0.7-1.3)$ & $1.1(0.8-1.3)$ & $0.9(0.6-1.2)$ \\
\hline Home healthcare $^{\mathrm{b}}$ & $0.9(0.6-1.3)$ & $1.9(1.2-3.0)$ & $0.8(0.5-1.3)$ & $1.4(0.8-2.3)$ & $0.7(0.4-1.1)$ & $1.0(0.5-1.7)$ \\
\hline Domestic help ${ }^{b}$ & $1.0(0.7-1.6)$ & $1.8(1.1-3.0)$ & $1.1(0.7-1.8)$ & $1.4(0.8-2.5)$ & $1.1(0.6-1.8)$ & $1.2(0.7-2.3)$ \\
\hline
\end{tabular}

In bold Significant ORs $(P$ value $<0.05)$

${ }^{a}$ Normal weight is the reference $(\mathrm{OR}=1)$

${ }^{\mathrm{b}}$ Greece and Switzerland excluded from that analysis (see Research Methods and Procedures section)

Model 1: adjusted for age and country

Model 2: adjusted as for model $1+$ socio-economic status, smoking, physical activity and alcohol consumption

Model 3: adjusted as for model $2+$ cardiovascular diseases, high blood pressure, high cholesterol, diabetes and arthritis

as an effect modifier of the BMI-healthcare utilization association. Interaction effects were ruled out in the modeling process and after performing country-specific analyses, except for the BMI*country of residence interaction for the use of specialist care. However, these countrylevel associations, showing decreased odds ratios for specialist care were not statistically significant and remained unexplained.

With respect to higher ambulatory care and medication use, these findings are consistent with previously published studies and confirm the impact that overweight and obesity are shown to have on the US healthcare systems, whether authors stratified their analysis by gender (Leon-Munoz et al. 2005; Andreyeva et al. 2004; Reidpath et al. 2002) or not (Bertakis and Azari 2005; von Lengerke et al. 2005; Raebel et al. 2004; Luchsinger et al. 2003; Ostbye et al. 2002; Quesenberry et al. 1999; Trakas et al. 1999), or considered women only (Meisinger et al. 2004; Guallar-Castillon et al.
2002). The most likely explanation may be that the treatment of obesity itself, and not of obesity-related diseases only, leads to increased healthcare utilization. Another might be that physicians, aware of the increased risk associated with higher BMI, propose different healthcare schedules to their overweight and obese patients. However, it is surprising to see that men and women showed such a similar ambulatory care and medication use, if we take into account the fact that associations between BMI and health complaints or disability seem to differ between genders. In fact, overweight/obese women are more likely to report symptoms and physical disability than overweight/obese men (Patterson et al. 2004; Lean et al. 1999).

With regard to hospitalization, which has not been consistently shown to be related to BMI (Bertakis and Azari 2005; von Lengerke et al. 2005; Andreyeva et al. 2004; Luchsinger et al. 2003; Guallar-Castillon et al. 2002; Quesenberry et al. 1999; Trakas et al. 1999), it remains 
unclear why overweight men were at decreased risk of, and obese women at increased risk of hospitalization. While the latter could be related to the higher incidence of morbidity among obese individuals, the decreased use of hospitals by overweight men may parallel the absence of a relationship between overweight and negative health outcomes among elderly men that is sometimes described in the literature (Arterburn et al. 2004). However, we have to be cautious with the interpretation of the decreased risk of hospitalization of overweight men since its significance was only marginal, and exploration of other dimensions of hospital stays did not reveal significant odds ratios.

Unexpected is the finding that neither overweight nor obesity was associated with increased use of home healthcare or domestic help, despite the known relationship that exists between BMI and physical disability or functional limitations (Larrieu et al. 2004; Lean et al. 1999). Even though the situation in men could be partly explained by wives acting as caregiver in many households, this is unlikely to be an explanation for the care of overweight/ obese women themselves. More probably, the lack of significant associations is due to the relatively small number of disabled men and women having used those services during the previous 12 months, and also possibly due to the fact that these services are not always included in the countries' basic health insurance package.

Population attributable fractions focus attention on populations and give another perspective to the results that depends not only on the magnitude of the association (OR), but also on the prevalence of the exposure (overweight and obesity). Its use may be debatable here because the PAF calculation assumes causality, which cannot be confirmed with our cross-sectional data. However, an inverse causality (i.e., high utilization leads to excess weight) is very unlikely. Although fully adjusted ORs were relatively high (overall, significant associations showed a 20 to $80 \%$ increased risk of utilization), the total burden for healthcare systems attributable to overweight and obesity varied between a low $3 \%$ and $23 \%$.

Despite the rising prevalence of obesity and aging of the population, findings from SHARE show that the burden overweight and obese individuals place on European healthcare systems is moderate. In terms of health services, this will particularly impact ambulatory care and medications. Future research may help explore the content and outcomes of ambulatory care visits, as measured by quality of care indicators, and further investigate how BMI impacts other healthcare utilization aspects such as nursing and social health services.

Acknowledgments This paper uses data from the early release 1 of SHARE 2004. This release may contain errors that will be corrected in later releases. The SHARE data collection has been primarily funded by the European Commission through the 5th framework program (project QLK6-CT-2001-00360 in the thematic program Quality of Life). Additional funding came from the US National Institute on Aging (U01 AG09740-13S2, P01 AG005842, P01 AG08291, P30 AG12815, Y1-AG-4553-01 and OGHA 04-064). Data collection in Austria (through the Austrian Science Fund, FWF), Belgium (through the Belgian Science Policy Office) and Switzerland (through BBW/ OFES/UFES) was nationally funded. The SHARE data set was introduced in Börsch-Supan et al. (2005); methodological details are contained in Börsch-Supan and Jürges (2005).

Conflict of interest statement Both authors affirm that there is no actual or potential conflict of interest in relation to this article and no financial interest/arrangement with one or more organizations that could be perceived as a real or apparent conflict of interest in the context of the subject of this article.

\section{References}

Andreyeva T, Sturm R, Ringel JS (2004) Moderate and severe obesity have large differences in health care costs. Obes Res 12:19361943

Arterburn DE, McDonell MB, Hedrick SC, Diehr P, Fihn SD (2004) Association of body weight with condition-specific quality of life in male veterans. Am J Med 117:738-746

Bertakis KD, Azari R (2005) Obesity and the use of health care services. Obes Res 13:372-379

Börsch-Supan A, Jürges H (2005) The survey of health, ageing and retirement in Europe: methodology. Mannheim Research Institute for the Economics of Aging (MEA), Mannheim

Börsch-Supan A, Hank K, Jürges H (2005) A new comprehensive and international view on ageing: introducing the "Survey of Health, Ageing and Retirement in Europe". Eur J Ageing 2:245-253

Colombo F, Tapay N (2004) Private health insurance in OECD countries: the benefits and costs for individuals and health systems. OECD Publishing, Paris

Connor Gorber S, Tremblay M, Moher D, Gorber B (2007) A comparison of direct vs. self-reported measures for assessing height, weight and body mass index: a systematic review. Obes Rev. Published article online 26-Jan-2007, DOI: 10.1111/j.1467-789X.2007.00347.x

Field AE, Coakley EH, Must A, Spadano JL, Laird N, Dietz WH et al (2001) Impact of overweight on the risk of developing common chronic diseases during a 10-year period. Arch Intern Med 161:1581-1586

Flegal KM, Carroll MD, Ogden CL, Johnson CL (2002) Prevalence and trends in obesity among US adults, 1999-2000. JAMA 288:1723-1727

Fontaine KR, Barofsky I (2001) Obesity and health-related quality of life. Obes Rev 2:173-182

Fontaine KR, Faith MS, Allison DB, Cheskin LJ (1998) Body weight and health care among women in the general population. Arch Fam Med 7:381-384

Groessl EJ, Kaplan RM, Barrett-Connor E, Ganiats TG (2004) Body mass index and quality of well-being in a community of older adults. Am J Prev Med 26:126-129

Guallar-Castillon P, Lopez GE, Lozano PL, Gutierrez-Fisac JL, Banegas Banegas JR, Lafuente Urdinguio PJ et al (2002) The relationship of overweight and obesity with subjective health and use of health-care services among Spanish women. Int J Obes Relat Metab Disord 26:247-252

Haslam DW, James WP (2005) Obesity. Lancet 366:1197-1209

Larrieu S, Peres K, Letenneur L, Berr C, Dartigues JF, Ritchie K et al (2004) Relationship between body mass index and different 
domains of disability in older persons: the $3 \mathrm{C}$ study. Int J Obes Relat Metab Disord 28:1555-1560

Lean ME, Han TS, Seidell JC (1999) Impairment of health and quality of life using new US federal guidelines for the identification of obesity. Arch Intern Med 159:837-843

Leon-Munoz LM, Guallar-Castillon P, Lopez Garcia E, Banegas JR, Gutierrez-Fisac JL, Rodriguez-Artalejo F (2005) Relationship of BMI, waist circumference, and weight change with use of health services by older adults. Obes Res 13:1398-1404

Lloyd-Sherlock P (2000) Population ageing in developed and developing regions: implications for health policy. Soc Sci Med 51:887-895

Luchsinger JA, Lee WN, Carrasquillo O, Rabinowitz D, Shea S (2003) Body mass index and hospitalization in the elderly. J Am Geriatr Soc 51:1615-1620

Meisinger C, Heier M, Loewel H (2004) The relationship between body weight and health care among German women. Obes Res 12:1473-1480

Mokdad AH, Bowman BA, Ford ES, Vinicor F, Marks JS, Koplan JP (2001) The continuing epidemics of obesity and diabetes in the United States. JAMA 286:1195-1200

Ostbye T, Taylor DH, Jung SH (2002) A longitudinal study of the effects of tobacco, smoking and other modifiable risk factors on ill health in middle-aged and old Americans: results fomr the Health and Retirement Study and Asset and Health Dynamics among the Oldest Old Survey. Prev Med 34:334-345
Palta M, Prineas RJ, Berman R, Hannan P (1982) Comparison of selfreported and measured height and weight. Am J Epidemiol 115:223-230

Patterson RE, Frank LL, Kristal AR, White E (2004) A comprehensive examination of health conditions associated with obesity in older adults. Am J Prev Med 27:385-390

Quesenberry CP Jr, Caan B, Jacobson A (1999) Obesity, health services use, and health care costs among members of a health maintenance organization. Arch Intern Med 158:466-472

Raebel MA, Malone DC, Conner DA, Xu S, Porter JA, Lanty FA (2004) Health services use and health care costs of obese and non obese individuals. Arch Intern Med 164:2135-2140

Reidpath DD, Crawford D, Tilgner L, Gibbons C (2002) Relationship between body mass index and the use of healthcare services in Australia. Obes Res 10:526-531

Rockhill B, Newman B, Weinberg C (1998) Use and misuse of population attributable fractions. Am J Public Health 88:15-19

Sturm R, Ringel JS, Andreyeva T (2004) Increasing obesity rates and disability trends. Health Aff (Millwood) 23:199-205

Trakas K, Lawrence K, Shear NH (1999) Utilization of health care resources by obese Canadians. CMAJ 160:1457-1462

von Lengerke T, Happich M, Reitmeir P, John J for the KORA Study Group (2005) Utilization of out- and inpatient health services by obese adults: a population-based study in the Augsburg region, Germany. Gesundheitswesen 67(Suppl 1):S150-S157 